\title{
The Fast and Slow Afterhyperpolarizations Are Differentially Modulated in Hippocampal Neurons by Aging and Learning
}

\author{
Elizabeth A. Matthews, John M. Linardakis, and John F. Disterhoft \\ Department of Physiology, Northwestern University, Chicago, Illinois 60611
}

Normal aging is usually accompanied by increased difficulty learning new information. One contributor to aging-related cognitive decline is decreased intrinsic excitability in aged neurons, leading to more difficulty processing inputs and remodeling synapses to store new memories. Two measures of excitability known to be altered by learning are the slow afterhyperpolarization (sAHP) after a burst of action potentials and the fast AHP (fAHP) after individual action potentials. Using rats trained in trace eyeblink conditioning, we examined how these two measures of excitability were modulated in CA1 hippocampal neurons from young (3-4 months) and aged (29-31 months) animals. Although both the SAHP and the fAHP were reduced by successful learning in both age groups, only the sAHP showed aging-related increases. The dichotomy of learning-related and aging-related effects on two very similar calcium-dependent potassium-driven hyperpolarizations suggests several interesting hypotheses for how cellular excitability is modulated by aging and learning.

\section{Introduction}

Normal, nonpathological aging results in slowing or impairment of learning across species, particularly affecting hippocampusdependent tasks (Jack et al., 2000). The cellular and molecular mechanisms responsible for these age-related learning impairments are not fully understood, but one important physiological property of neurons is known to be impaired by aging: cellular excitability (Wu et al., 2002). Analogous changes in excitability have been seen in learning (Disterhoft and Oh, 2006a) and related to synaptic function (Zhang and Linden, 2003).

Neuronal afterhyperpolarizations (AHP) can be described based on their temporal dynamics and underlying currents. The slow post-burst AHP (sAHP) can be further subdivided into a medium (50-100 ms) and a slow (1-2 s) component. The medium AHP is carried by apamin-sensitive SK (small- $\mathrm{K}^{+}$conductance) channels, but the channel(s) that carry the slow AHP are still unknown (Disterhoft and Oh, 2006a). Both components are calcium sensitive and will be referred to together as the sAHP for this study. The sAHP is increased in hippocampal cells from aging animals (Landfield and Pitler, 1984; Power et al., 2002), and this increase correlates with increased difficulty learning hippocampus-dependent tasks such as trace eyeblink conditioning (Moyer et al., 2000) and the Morris water maze (Tombaugh et al., 2005). Calcium currents and neuronal calcium handling capacity are also known to be altered with aging (Khachaturian, 1987; Landfield, 1987), and this could in part account for agingrelated increases in the sAHP (Kumar and Foster, 2004). In ad-

Received Jan. 23, 2009; revised March 3, 2009; accepted March 9, 2009

This work was supported by National Institutes of Health Grants F31 NS053434 (E.A.M.) and R37 AG08796 (J.F.D.). Behavioral training was done in the Behavioral Phenotyping Core at Northwestern University.

Correspondence should be addressed to Elizabeth A. Matthews, 303 E. Chicago Avenue, Ward 7-140, Chicago, IL 60611. E-mail: ElizabethMatthews2009@u.northwestern.edu.

D01:10.1523/JNEUROSCI.0384-09.2009

Copyright $\odot 2009$ Society for Neuroscience $\quad$ 0270-6474/09/294750-06\$15.00/0 dition to aging-related modulation, the sAHP is reduced by learning (Moyer et al., 1996).

The fast AHP (fAHP) lasts $2-5 \mathrm{~ms}$, repolarizes and follows action potentials, and is carried by the calcium- and voltagedependent BK channel (Storm, 1987). It has been reported recently that the fAHP is also modulated in the hippocampus after learning the trace eyeblink task (Matthews et al., 2008) and in the prefrontal cortex after extinction of fear conditioning (Santini et al., 2008). In this study, we investigated how normal, nonpathological aging interacts with the learning-related modulation of the sAHP and fAHP.

Young (3-4 months) and aging (29-31 months) rats were trained in trace eyeblink conditioning. In both age groups, some animals failed to learn the task. Comparisons of the sAHP and the fAHP were made between learner, nonlearner, pseudoconditioned, and naive animals within the same age group. As reported previously by our laboratory and others, the sAHP and the fAHP were both reduced in cells from animals that learned the task in both age groups. The sAHP and fAHP were then compared between age groups from animals in the same behavioral category. Interestingly, the fAHP did not show any aging-related alterations, whereas the sAHP was larger in control animals (nonlearner, pseudoconditioned, and naive) from the older group. This suggests that the cellular mechanisms responsible for modulating the calcium-activated potassium currents that mediate the sAHP and fAHP are differentially affected by the aging process.

\section{Materials and Methods}

Subjects. Experimental subjects were 3- to 4-month-old or 29- to 31month-old male F1 hybrid Fischer $344 \times$ Brown Norway rats. Animals were group housed in a climate-controlled room with a 14/10 h light/ dark cycle and ad libitum access to food and water. All procedures were approved by the Northwestern University Animal Care and Use Committee and conformed to National Institutes of Health standards (pub- 
lications number 80-23). All efforts were made to minimize animals' discomfort and the number of animals used. Behavioral groups were intentionally balanced between learners (young, 5; aged, 7), nonlearners (young, 6; aged, 7), pseudoconditioned (young, 6; aged, 8), and naive (young, 6; aged, 7) by J.M.L., whereas E.A.M. was kept blind to rat training history during recording and cellular data analyses.

Surgery. All surgeries were performed using sterile procedures. Animals were anesthetized with isofluorane gas. Eyes were kept moist with a thin layer of antibacterial ophthalmic ointment. Rats were positioned in a stereotaxic frame, with lambda and bregma equal in the vertical plane. All subjects were administered analgesic Buprenex $(0.06 \mathrm{mg} / \mathrm{kg}$, s.c.) to minimize postsurgical discomfort. The skull was exposed, and four stainless steel screws were inserted into the skull. Two Teflon-coated stainless steel wires were implanted in the eyelid and connected to a plastic strip connector to monitor electromyograph activity from the orbicularis oculi muscle. The strip connector was grounded and secured to the stainless steel screws using dental acrylic and allowed the EMG activity to be continuously monitored by computer during training. After implantation of the EMG wires and the strip connector, rats were allowed to recover and then returned to their home cage. Animals were given a minimum of $4 \mathrm{~d}$ to recover from surgery before training.

Eyeblink conditioning training. Trace eyeblink conditioning procedures described previously were followed (Weiss et al., 1999). Training sessions were conducted in a sound-attenuating chamber and controlled with a custom-designed LabVIEW (National Instruments) program; eyelid EMG data was integrated online during training. Animals were connected to the recording computer via the implanted connector strip; a short tether served the dual purpose of allowing EMG activity to be monitored and positioning an air-puff delivery tube in front of the eye while the rat was freely moving. The subjects then received one session of stimulus-free habituation to the training chamber lasting as long as a conditioning session, followed by five training sessions. Conditioned animals experienced 30 trials per session [30 s average intertrial interval (ITI)] for a total of 150 conditioned stimulus (CS) - unconditioned stimulus (US) pairings. Conditioned animals received a tone stimulus (CS, 80 $\mathrm{dB}, 250 \mathrm{~ms}$ ) paired with a corneal air puff (US, 3-5 psi, $100 \mathrm{~ms}$ ) with a 250 $\mathrm{ms}$ stimulus-free trace interval interposed. A correctly timed closure of the eye, defined as $>4$ SDs above baseline, occurring within the $100 \mathrm{~ms}$ preceding the air puff was defined as an adaptive conditioned response (CR). Pseudoconditioned animals experienced 30 tone trials and 30 airpuff trials in a random unpaired manner ( $15 \mathrm{~s}$ average ITI). The criterion for inclusion in the learner group was better than $60 \%$ adaptive responses by the final training session. Transverse hippocampal slices were made 24 hours after completion of training. Naive animals were handled $18-24 \mathrm{~h}$ before slices were made.

In vitro electrophysiology recordings. Unless otherwise stated, all reagents were obtained from Sigma. The experimenter was blind to the training status of the animal during all recordings and analyses. After deep halothane anesthesia, rats were decapitated, and the brain was quickly removed to ice-cold artificial CSF containing the following (in mM): $124 \mathrm{NaCl}, 2.5 \mathrm{KCl}, 1.25 \mathrm{NaH}_{2} \mathrm{PO}_{4}, 26 \mathrm{NaHCO}_{3}, 2.4 \mathrm{CaCl}_{2}, 2$ $\mathrm{MgSO}_{4}$, and 25 glucose, $\mathrm{pH} 7.4$ (bubbled with $95 \% / 5 \% \mathrm{O}_{2} / \mathrm{CO}_{2}$ ). Transverse slices $(300 \mu \mathrm{m})$ from the dorsal half of the hippocampus were made using a Leica VT1000s vibratome. Slices were incubated at $34^{\circ} \mathrm{C}$ for 30 min after slicing and at room temperature for $1 \mathrm{~h}$ before the start of recording. Thin-walled borosilicate recording electrodes with a resistance of 3-5 $\mathrm{M} \Omega$ and were filled with internal solution containing the following: $115 \mathrm{~mm}$ potassium methylsulfate (Thermo Fisher Scientific), $20 \mathrm{~mm} \mathrm{KCl,} 10 \mathrm{~mm}$ sodium phosophocreatine, $10 \mathrm{~mm}$ HEPES, $2 \mathrm{~mm}$ $\mathrm{Mg}_{2} \mathrm{ATP}, 0.3 \mathrm{~mm} \mathrm{Na}_{3} \mathrm{GTP}$, and in some cases $0.1 \%$ biocytin. The $\mathrm{pH}$ was adjusted with $\mathrm{KOH}$ to 7.45; osmolarity was between 280 and 290 Osm. Slices were transferred to a temperature-controlled recording chamber $\left(34^{\circ} \mathrm{C}\right)$ mounted on a Zeiss microscope equipped with a differential interference contrast camera. CA1 pyramidal neurons were visually selected, and high-resistance ( $>1 \mathrm{G} \Omega$ ) seals were obtained. To be included in the study, cells were required to have a resting membrane potential between -58 and $-70 \mathrm{mV}$, an input resistance of $>25 \mathrm{M} \Omega$ that remained stable throughout the recording, and an action potential height at least $70 \mathrm{mV}$ above the holding potential. Recordings were made in current-clamp mode using a Dagan 3200C amplifier; electrode capacitance and series resistance were compensated and systematically checked throughout the recording. Cells were held at $-65 \mathrm{mV}$ with current injection.

In vitro data collection and analyses. Recordings were acquired and analyzed using pClamp 9.2 on a desktop personal computer and digitized using a Digidata 1322A analog-to-digital converter. Statistical tests were applied using StatView. Significant differences were evaluated using oneway or repeated measures ANOVA when appropriate, followed by Fisher's PLSD post hoc tests. All data are reported as group, mean \pm SEM.

\section{Results}

\section{Performance on trace eyeblink conditioning}

Both young and aged animals received the same number of training trials. Animals were either conditioned with paired tone and air puff or pseudoconditioned with random tone and air-puff presentations during five training sessions (see Materials and Methods). Among those animals trained with paired stimuli, assignment to a learning category was based on the animal's performance on the last training session. Animals that did not reach a level of $60 \%$ adaptive CRs were deemed nonlearners. Animals performing at or above $60 \%$ during the last session were assigned to the learner group. Within both age categories, some animals failed to learn to the $60 \%$ criterion. Unlike aging rabbits (Moyer et al., 2000), if an aging rat learned the task, there was no reduction in the rate at which the learning occurred. This is in agreement with studies showing that only senescent rats $(>34$ months) have slower learning rates (Knuttinen et al., 2001). The rate of learning, number of CRs, and timing of CRs were indistinguishable between young and aged animals that learned the task. Likewise, the CRs given by nonlearners were not different between age groups. Finally, young and aged pseudoconditioned animals showed similar random eye closures and responded with identical unconditioned responses to the air puff. Performance on the trace eyeblink conditioning task by young and aged animals in all training groups is shown in Figure 1.

\section{Learning-related changes in excitability}

Intrinsic properties of cells included in the study were not different between learning conditions within the same age category. Input resistance $\left(R_{\text {input }}\right)$ (calculated from the steady-state membrane voltage during a brief $-50 \mathrm{pA}$ step), resting membrane potential $\left(V_{\text {rest }}\right)$ (the membrane potential with no current injection), action potential threshold $\left(V_{\text {thresh }}\right)$ (defined as the point at which the first derivative of the membrane potential equaled 20 $\mathrm{mV} / \mathrm{ms}$ ), and action potential height (AP) (measured as peak distance from the holding potential) are summarized in Table 1 but showed no learning-related differences.

Recordings of cells from both young and aged animals that learned the trace eyeblink task to the criterion level showed increased excitability as measured by reductions in the SAHP and the fAHP. Slow AHPs were somatically elicited with 25 1.2-nA current pulses at $50 \mathrm{~Hz}$. After zeroing the baseline, the AHP was measured as the negative peak after the membrane potential recrossed zero after the last action potential (Fig. 2C). The slow component of the AHP was measured $1 \mathrm{~s}$ after the membrane potential crossed zero after the last action potential. Young learners showed reduced peak and 1 s sAHPs compared with nonlearners, pseudoconditioned, and naive animals (peak, $F_{(3,52)}=$ 2.882, $\left.p<0.04 ; 1 \mathrm{~s}, F_{(3,52)}=2.816, p<0.05\right)$. Aged learners also showed significantly reduced peak and $1 \mathrm{~s}$ sAHPs compared with controls of the same age group (peak, $F_{(3,55)}=6.955, p<0.001$; $1 \mathrm{~s}, F_{(3,55)}=4.262, p<0.009$ ). (Fig. $2 A$ )

The fAHP was measured from trains of action potentials elic- 

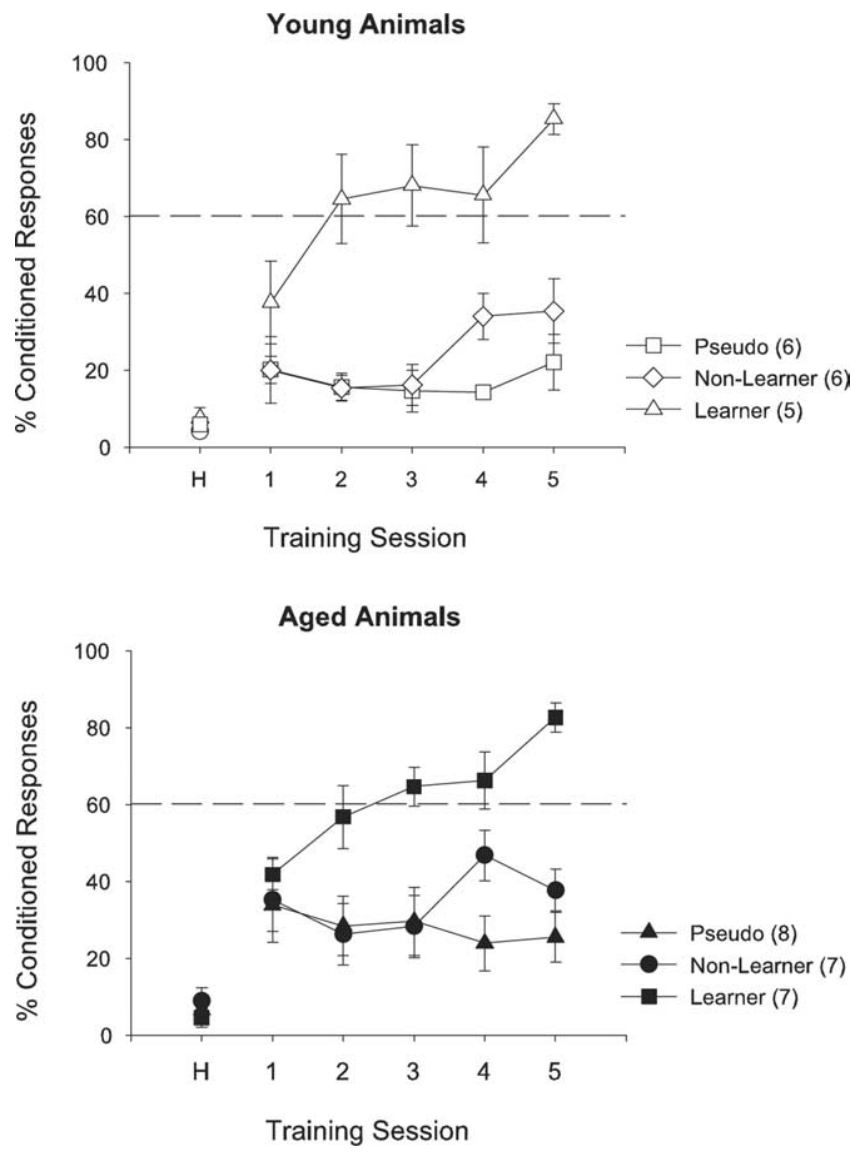

Figure 1. Performance on trace eyeblink task by young and aged animals. Young and aged animals were included in the learner category if their performance at the eyeblink task by the last training session exceeded $60 \%$ conditioned responses (dashed line). Animals that failed to reach criterion were included in the nonlearner group. Groups were intentionally balanced between all behavioral categories with the investigator doing the recording remaining blind to animal training history. The random response rate for pseudoconditioned animals is shown for comparison to the nonlearners. There was no difference in the rate of learning between young and aged animals that learned the task or in the responses of the pseudoconditioned and nonlearners.

ited with an $800 \mathrm{~ms}$ somatic current step sufficient to generate at least four action potentials. The fAHP was measured as both the negative-going peak relative to the action potential threshold and the absolute negative peak after the action potential peak. Averaged fAHPs for the first six action potentials in the train are shown in Figure $2 \mathrm{~B}$. Cells from young learners had reduced fAHPs in the early action potentials of a train compared with age-matched controls $\left(F_{(3,47)}=2871, p<0.05\right)$. Cells from aged learners showed similar reductions in the fAHP compared with age-matched controls $\left(F_{(3,54)}=4.207, p<0.01\right)$. It is significant that learning-related differences in the fAHP are seen only in early action potentials in a train. The BK channel inactivates during trains of activity (Shao et al., 1999), reducing the contribution of the BK to AP repolarization and the fAHP (Matthews et al., 2008). It is expected that learning-related differences attributable to BK channel alterations would be found only during early action potentials in a train, before channel inactivation. Although the fAHP decreased during the train in all groups, the finding that the learning-related reductions of the fAHP were seen in early action potentials is consistent with learning-related alterations to an inactivating current, presumably $I_{\mathrm{BK}}$.

The effect of BK-channel block on firing frequency was tested by bath applying paxilline $(10 \mu \mathrm{M})$. Cells were induced to fire at frequencies between 1.25 and $10 \mathrm{~Hz}$ using an $800 \mathrm{~ms}$ step current injection. After paxilline application, the firing frequency to the same current injections was increased without any accompanying change in input resistance, as has been reported previously (Nelson et al., 2003; Matthews et al., 2008). Although all cells showed some increase in firing frequency after drug application, the increase in frequency was significantly greater in cells from control animals than in cells from animals that learned trace conditioning, indicating that there was a different level of BKchannel modulation of firing frequency between the groups after learning (young, $F_{(3,48)}=2.887, p<0.05$; aged, $F_{(3,53)}=3.252$, $p<0.03$ ). This effect was observed previously for neurons from young conditioned rats (Matthews et al., 2008). The learningrelated increase in firing frequency was observed in both young and aged groups (Data not shown). The greater effect of paxilline on cells from control animals is consistent with the observed learning-related reduction of the fAHP in both young and aged animals.

\section{Aging-related changes in excitability}

No aging-related changes were seen in $R_{\text {input }}, V_{\text {rest }}$, or AP height. Action potential threshold was increased in cells from aging animals in the learner and nonlearner groups relative to cells from young animals in the same group (Table 1) (learner, $F_{(1,30)}=$ 8.378, $p<0.01$; nonlearner, $\left.F_{(1,33)}=6.133, p<0.05\right)$. We did not find any aging-related difference in resting membrane potential as has been reported in aging rabbits (Power et al., 2002).

It has been reported previously that cells from naive aged rats and rabbits exhibit larger sAHPs and reduced excitability (Landfield and Pitler, 1984; Moyer et al., 2000; Power et al., 2002). We confirmed this aging-related increase in the sAHP in rats. Because of the learning-related changes in the sAHP reported above, the sAHP was compared between young and aged animals within each learning category. Neurons from the control groups showed an aging-related increase in the peak and $1 \mathrm{~s}$ sAHP (Fig. $3 A, C$ ) (naive, $F_{(1,21)}=4.472, p=0.05$; pseudo, $F_{(1,27)}=4.475, p=0.04$; nonlearner, $\left.F_{(1,34)}=5.260, p=0.02\right)$. There was no difference in the peak and $1 \mathrm{~s}$ measures between young and old animals that succeeded in learning the task (Fig. $3 C)\left(F_{(1,25)}=0.85, p=0.36\right.$ ). It is interesting to note that the learning performance for young and aged rats that succeeded in learning the task were indistinguishable. Likewise, the sAHP from aged animals that successfully learned the task were similar to the sAHP from young animals that learned, suggesting a correlation between sAHP plasticity and learning capacity.

The effect of aging on the fAHP has not been studied previously. We compared the peak of the fAHP of the first four action potentials in a train between young and old control animals and found no age-related changes in the fAHP (Fig. $3 B$ ) (learner, $F_{(1,23)}=0.05, p=0.8$; naive, $F_{(1,22)}=0.25, p=0.6$; pseudo, $F_{(1,26)}$ $=0.02, p=0.9$; nonlearner, $\left.F_{(1,29)}=0.20, p=0.7\right)$. Additional comparison by learning category did not reveal aging-related changes in the fAHP in any behavioral group (Fig. $3 C$ ). Because the fAHP was measured relative to the AP threshold, the slight aging-related increase in AP threshold in the learner and nonlearner groups might mask an aging-related decrease in the fAHP in these groups. However, using the absolute peak voltage measure of the fAHP, there was still no difference found between the fAHPs of young and aged cells in the learner and nonlearner groups. As in young cells, paxilline caused an increase in firing frequency in cells of aged animals in a learning-dependent manner (see above, Learning-related changes in excitability), but the 
Table 1. Intrinsic properties of cells by age and learning categories

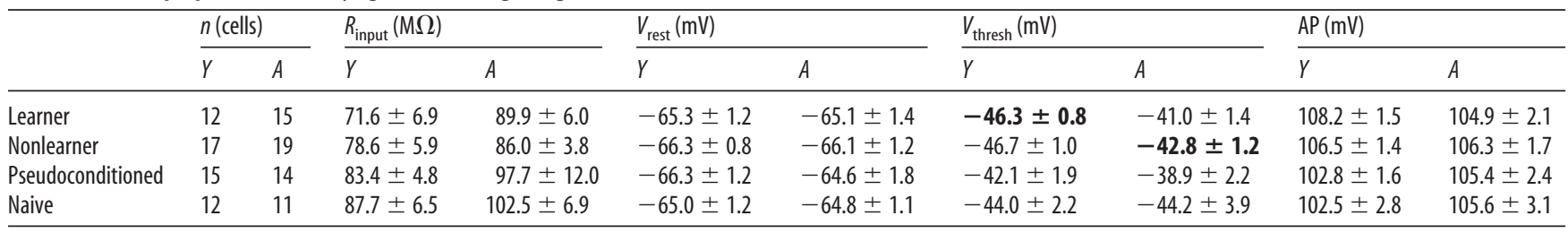

Input resistance was calculated from the steady-state membrane voltage during a brief $-50 \mathrm{pA}$ step. Resting membrane potential was defined as the membrane potential with no current injection. Action potential threshold was defined as the point at which the first derivative of the membrane potential equaled $20 \mathrm{mV} / \mathrm{ms}$. Action potential height was measured as peak distance from the holding potential. There were significant differences in the threshold between young and aged cells in the learner and nonlearner groups (bold: learner, $F_{(1,30)}=8.378, p<0.01$; nonlearner, $F_{(1,33)}=6.133, p<0.05$ ). There was a trend toward increased input resistance between young and aged cells in the learner group (learner, $\left.F_{(1,30)}=3.343, p=0.08\right)$.
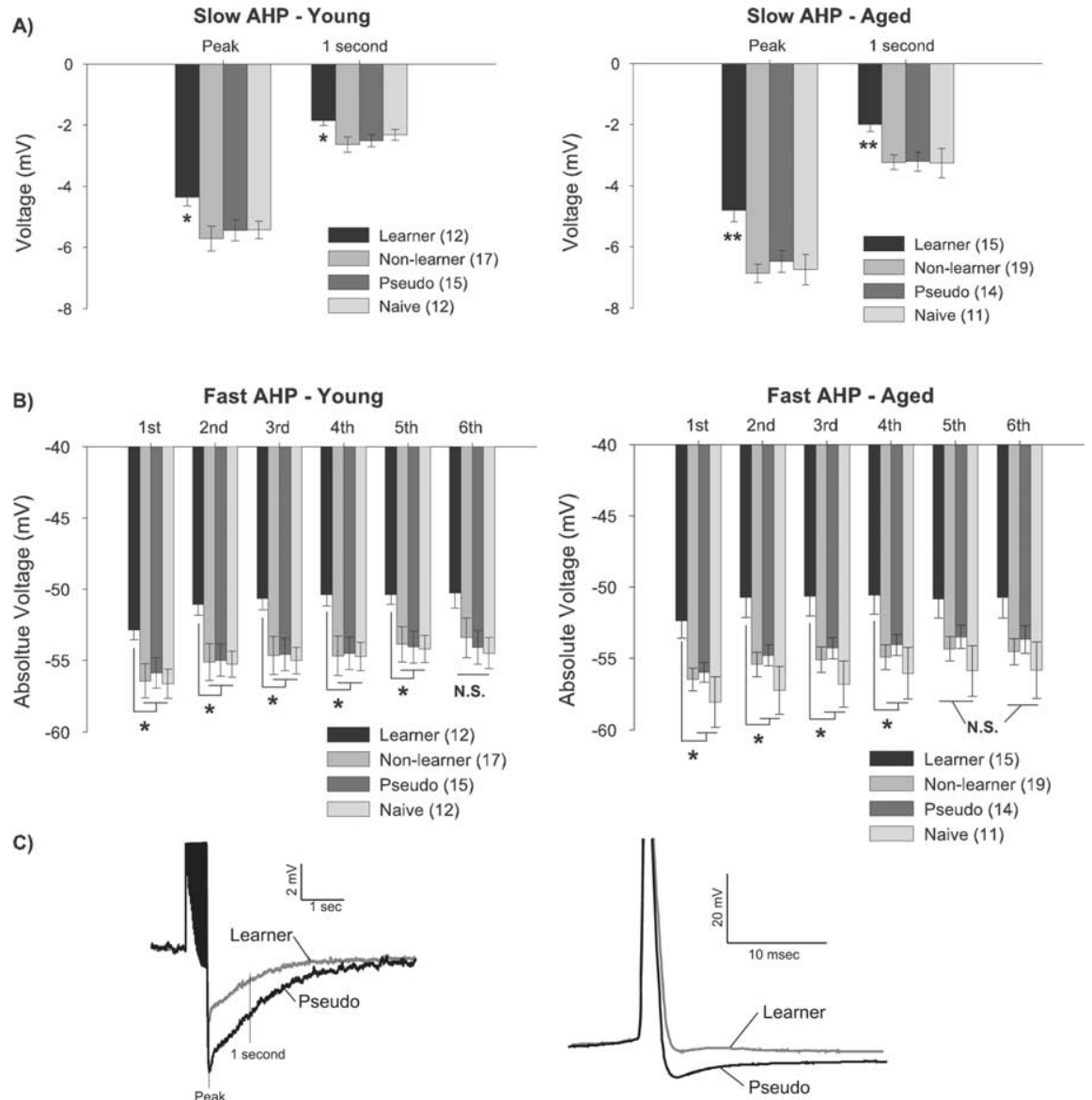

Figure 2. Learning-related changes in the SAHP and fAHP. Learning increases cellular excitability by decreasing the SAHP and the fAHP in both young and aged cells. $A$, The peak and $1 \mathrm{~s}$ measures of the SAHP from young (left) and aged (right) cells is reduced after successfully learning trace eyeblink conditioning (young - peak: learner, $-4.36 \pm 0.28$; nonlearner, $-5.71 \pm 0.41$; pseudo, $-5.44 \pm 0.34 ;$ naive, $-5.46 \pm 0.27 ; 1 \mathrm{~s},-1.85 \pm 0.16 ;-2.64 \pm 0.25,-2.58 \pm 0.19,-2.42 \pm 0.16)$ (aged peak: learner, $-4.81 \pm 0.37$; nonlearner, $-6.87 \pm 0.30$; pseudo, $-6.48 \pm 0.35$; naive, $-6.74 \pm 0.50 ; 1 \mathrm{~s},-2.00 \pm 0.23$, $-3.23 \pm 0.24,-3.21 \pm 0.31,-3.27 \pm 0.48)$. $\boldsymbol{B}$, The absolute fAHP peak voltage is reduced in a train of action potentials in both age groups after learning (first fAHP, young: learner, $-52.89 \pm 0.69$; nonlearner, $-57.25 \pm 1.17$; pseudo, $-55.85 \pm$ 1.07; naive, $-56.59 \pm 1.02$ ) (first fAHP, aged: learner, $-52.22 \pm 1.04$; nonlearner, $-56.44 \pm 0.79 ;$ pseudo, $-55.90 \pm 0.71$; naive, $-57.31 \pm 1.92$ ). C, Example traces show the SAHP (left), with lines indicating the peak and $1 \mathrm{~s}$ measurements and the fAHP (right) for cells from aged animals that learned the trace eyeblink task or were pseudoconditioned. ${ }^{*} p<0.05,{ }^{* *} p<0.01$.

degree of increased firing was not different from young cells (data not shown). The similar effect of BK-channel block between young and aged cells is consistent with the observation that the fAHP is reduced by learning but is not altered by aging.

\section{Discussion}

Learning-related increases in intrinsic cellular excitability via the reduction of the sAHP have been shown using several tasks, including Morris water maze learning in rats (Oh et al., 2003), eyeblink conditioning in rats (Kuo et al., 2008) and rabbits (Moyer et al., 1996), and associative conditioning in invertebrates (Alkon, 1984). The reduction of the sAHP is proposed to be caused in part by altered calcium influx, altered phosphorylation of the relevant channel(s) by either PKC (Van der Zee et al., 1997; Seroussi et al., 2002) or PKA (Oh et al., 2009), or a combination of these factors. Learning-related reductions of the fAHP have been shown in rats after eyeblink conditioning (Matthews et al., 2008) and after extinction of fear conditioning (Santini et al., 2008). The reduction of the fAHP could occur in parallel to alterations in the sAHP as a result of similar or identical factors. However, a recent finding hints that the SAHP and fAHP may be modulated by learning through different mechanisms. When the sAHP is pharmacologically reduced in vivo, aging-related learning deficits are reversed (Disterhoft and Oh, 2006b). In contrast, reducing the fAHP in vivo using BKchannel blockade impairs rather than improves learning in young animals (Matthews and Disterhoft, 2009). Nevertheless, the finding that aging differentially affects the sAHP and the fAHP was surprising. Both hyperpolarizations are caused by calcium-dependent potassium currents, and both are modulated by learning. Why might the fAHP be protected from agerelated increases? The divergence of aging effects on these similar currents may reveal important points in which the regulation of cellular excitability is modulated by learning and compromised in aging.

Two competing theories of aging suggest that the age-related alteration in the control of intrinsic excitability is attributable to either cholinergic or calcium dysregulation. The cholinergic hypothesis of aging proposes that a loss of cholinergic tone with aging (Bartus et al., 1982) contributes to aging-related cognitive decline. Activation of muscarinic acetylcholine (ACh) receptors reduces the sAHP in vitro (Power et al., 2001). It is possible that a loss of ACh in aging contributes in the aging-related increase in the sAHP and an overall loss of excitability. Additionally, increasing cholinergic tone in vivo through ACh receptor agonists (Weiss et al., 2000) or cholinesterase inhibitors (Kronforst-Collins et al., 1997) im- 
proves trace eyeblink conditioning performance in aging animals. The effect of ACh on BK channels that mediate the fAHP has been studied in vestibular hair cells in which ACh increases BK currents via increasing calcium influx through nicotinic ACh receptors (Kong et al., 2007); increased BK currents would result in a larger fAHP, the opposite of the effect of ACh on the sAHP channel(s). Therefore, a loss of ACh in aging should lead to a smaller fAHP in aging cells. Unfortunately, little is known about the effect of ACh on BK channels in hippocampal neurons. An additional confound is that the action of muscarinic $\mathrm{ACh}$ receptors is quite different from that of nicotinic ACh receptors, making it difficult to compare the results of the experiments in vestibular hair cells with those in hippocampus. Perhaps the different modulation of the sAHP and AAHP by ACh may provide one reason that the fAHP is preserved, whereas the sAHP is increased by loss of cholinergic input in aging.

The calcium hypothesis of aging proposes that aging neurons experience a loss of the mechanisms that maintain cytosolic $\mathrm{Ca}^{2+}$ concentration, resulting in increased calcium levels throughout the brain (Landfield, 1987; Khachaturian, 1994) or in dysregulation of localized calcium sources and stores (Foster, 2007). This hypothesis is well supported by several studies that find larger $\mathrm{Ca}^{2+}$ action potentials in aging neurons (Pitler and Landfield, 1990; Moyer and Disterhoft, 1994), probably attributable to increased functional L-type $\mathrm{Ca}^{2+}$ channels (Campbell et al., 1996; Thibault and Landfield, 1996) or altered phosphorylation of L-type $\mathrm{Ca}^{2+}$ channels (Davare and Hell, 2003). The strong calcium dependence of the BK channel would lead us to expect that the fAHP should be more vulnerable to aging-related dysregulation of $\mathrm{Ca}^{2+}$, and the linking of BK channels with L-type channels (Marrion and Tavalin, 1998) would lead us to hypothesize that the BK-mediated fAHP would be enhanced by any increase in L-type current. However, other studies indicate that the BK channel is functionally linked to the N-type channel rather than the L-type channel (Loane et al., 2007). Whatever the source of calcium for BK activation, Müller et al. (2007) show that the calcium source(s) must be physically very close to the calcium sensor of the BK channel. This close positioning of calcium source and potassium channel would make the BKmediated fAHP sensitive to age-related alterations in that channel only. It would appear that the BK channel is protected from general cell-wide dysregulation of calcium by the specificity of its calcium source. Other sources, such as internal stores (Shah and Haylett, 2000), are involved in generating the sAHP, and if any of these become larger with age (Gant et al., 2006), the sAHP will be affected but not the fAHP. This line of reasoning also suggests that the learning-
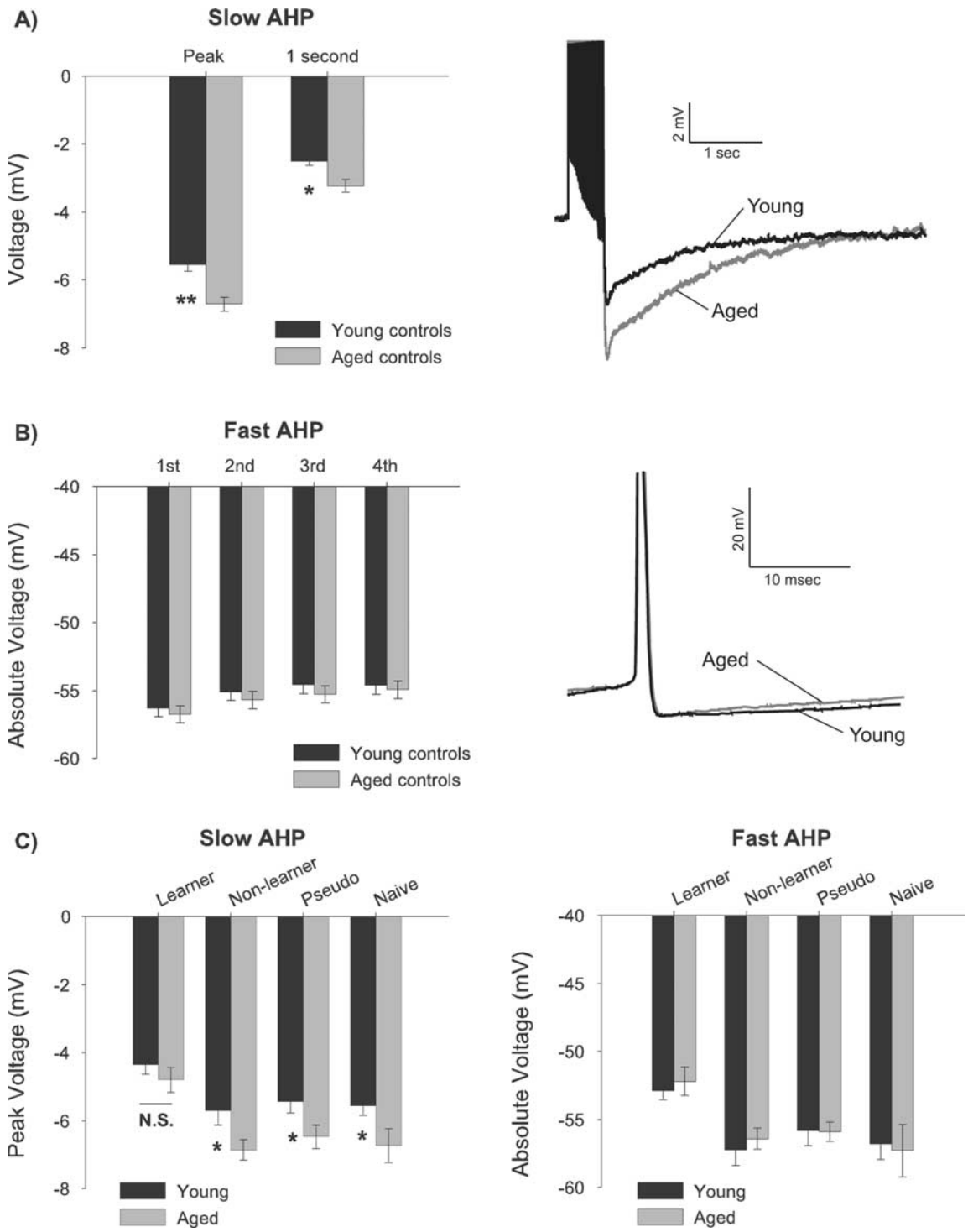

Figure 3. Aging-related changes in the SAHP but not the fAHP. Normal aging increases the SAHP but leaves the fAHP unaffected. $\boldsymbol{A}$, Because learning-related reductions of the SAHP and FAHP were shown previously for the learner versus control animals, aging-related changes were compared only between the control groups (pseudoconditioned, nonlearner, and naive combined). Both the peak and the $1 \mathrm{~s}$ measures of the SAHP were enhanced in aged control cells (peak: young, $-5.55 \pm 0.20$; aged, $-6.71 \pm 0.21 ; 1 \mathrm{~s}$ : young, $-2.56 \pm 0.12$; aged, $-3.24 \pm 0.18)$. $\boldsymbol{B}$, However, the control groups showed no age-related differences in the absolute fAHP peak voltage for the action potentials in a train (first fAHP: young, $-56.30 \pm 0.63$; aged, $-56.75 \pm 0.62$ ). Example traces from cells from young and aged naive animals are shown at far right. $C$, The peak sAHP from both young and aged animals that succeeded in learning the task were not different (learner: young, $-4.36 \pm 0.28$; aged, $-4.81 \pm$ 0.37). However, age-related increases in the SAHP were seen in cells from all the control groups. Comparing the fAHP values for the first action potential in a train for each behavioral group reveals that none of the groups showed age-related differences in the fAHP. ${ }^{*} p<0.05 ;{ }^{* *} p<0.001$.

related changes in the fAHP are not attributable to a cell-wide learning-related change in $\mathrm{Ca}^{2+}$ influx, although learning-related changes in the SAHP may be.

Finally, age-related increases in the sAHP could be attributable to increased expression of the channels for the sAHP. The identity of the sAHP channel(s) is still unknown, making it difficult to test this hypothesis. The fAHP is primarily mediated by the BK channel, and BK channel expression seems to be constant in aging cerebral cardiovasculature (Nishimaru et al., 2004), although this has not been tested in neurons. Our results reported above could be explained if the as-yet-unidentified sAHP channel is upregulated during aging, whereas BK channel expression re- 
mains constant. Given this hypothesis, the relevant question for understanding learning would be whether learning-related reductions in both the sAHP and the fAHP were attributable to altered gene expression or rather to learning-mediated changes in channel function or calcium dynamics.

The results of this study establish that the increase of intrinsic cellular excitability during learning and the decrease in excitability during aging are not simply the reverse of each other. Determining the points at which the molecular pathways that modulate the slow and fast AHP diverge offers to improve our understanding of how the aging process can impinge on the maintenance of cellular excitability.

\section{References}

Alkon DL (1984) Calcium-mediated reduction of ionic currents: a biophysical memory trace. Science 226:1037-1045.

Bartus RT, Dean RL 3rd, Beer B, Lippa AS (1982) The cholinergic hypothesis of geriatric memory dysfunction. Science 217:408-414.

Campbell LW, Hao SY, Thibault O, Blalock EM, Landfield PW (1996) Aging changes in voltage-gated calcium currents in hippocampal CA1 neurons. J Neurosci 16:6286-6295.

Davare MA, Hell JW (2003) Increased phosphorylation of the neuronal L-type $\mathrm{Ca}^{2+}$ channel $\mathrm{Ca}_{\mathrm{v}} 1.2$ during aging. Proc Natl Acad Sci U S A 100:16018-16023.

Disterhoft JF, Oh MM (2006a) Learning, aging and intrinsic neuronal plasticity. Trends Neurosci 29:587-599.

Disterhoft JF, Oh MM (2006b) Pharmacological and molecular enhancement of learning in aging and Alzheimer's disease. J Physiol Paris 99:180-192.

Foster TC (2007) Calcium homeostasis and modulation of synaptic plasticity in the aged brain. Aging Cell 6:319-325.

Gant JC, Sama MM, Landfield PW, Thibault O (2006) Early and simultaneous emergence of multiple hippocampal biomarkers of aging is mediated by $\mathrm{Ca}^{2+}$-induced $\mathrm{Ca}^{2+}$ release. J Neurosci 26:3482-3490.

Jack CR Jr, Petersen RC, Xu Y, O’Brien PC, Smith GE, Ivnik RJ, Boeve BF, Tangalos EG, Kokmen E (2000) Rates of hippocampal atrophy correlate with change in clinical status in aging and AD. Neurology 55:484-489.

Khachaturian ZS (1987) Hypothesis on the regulation of cytosol calcium concentration and the aging brain. Neurobiol Aging 8:345-346.

Khachaturian ZS (1994) Calcium hypothesis of Alzheimer's disease and brain aging. Ann NY Acad Sci 747:1-11.

Knuttinen MG, Gamelli AE, Weiss C, Power JM, Disterhoft JF (2001) Agerelated effects on eyeblink conditioning in the $\mathrm{F} 344 \mathrm{x} \mathrm{BN}$ F1 hybrid rat. Neurobiol Aging 22:1-8.

Kong WJ, Guo CK, Zhang XW, Chen X, Zhang S, Li GQ, Li ZW, Van Cauwenberge $P$ (2007) The coupling of acetylcholine-induced BK channel and calcium channel in guinea pig saccular type II vestibular hair cells. Brain Res 1129:110-115.

Kronforst-Collins MA, Moriearty PL, Schmidt B, Disterhoft JF (1997) Metrifonate improves associative learning and retention in aging rabbits. Behav Neurosci 111:1031-1040.

Kumar A, Foster TC (2004) Enhanced long-term potentiation during aging is masked by processes involving intracellular calcium stores. J Neurophysiol 91:2437-2444.

Kuo AG, Lee G, McKay BM, Disterhoft JF (2008) Enhanced neuronal excitability in rat CA1 pyramidal neurons following trace eyeblink conditioning acquisition is not due to alterations in I M. Neurobiol Learn Mem $89: 125-133$.

Landfield PW (1987) "Increased calcium-current" hypothesis of brain aging. Neurobiol Aging 8:346-347.

Landfield PW, Pitler TA (1984) Prolonged $\mathrm{Ca}^{2+}$-dependent afterhyperpolarizations in hippocampal neurons of aged rats. Science 226:1089-1092.

Loane DJ, Lima PA, Marrion NV (2007) Co-assembly of N-type $\mathrm{Ca}^{2+}$ and BK channels underlies functional coupling in rat brain. J Cell Sci 120:985-995.

Marrion NV, Tavalin SJ (1998) Selective activation of $\mathrm{Ca}^{2+}$-activated $\mathrm{K}^{+}$ channels by co-localized $\mathrm{Ca}^{2+}$ channels in hippocampal neurons. Nature 395:900-905.

Matthews EA, Disterhoft JF (2009) Blocking the BK channel impedes acquisition of trace eyeblink conditioning. Learn Mem 16:106-109.
Matthews EA, Weible AP, Shah S, Disterhoft JF (2008) The BK-mediated fAHP is modulated by learning a hippocampus-dependent task. Proc Natl Acad Sci U S A 105:15154-15159.

Moyer JR Jr, Disterhoft JF (1994) Nimodipine decreases calcium action potentials in rabbit hippocampal CA1 neurons in an age-dependent and concentration-dependent manner. Hippocampus 4:11-17.

Moyer JR Jr, Thompson LT, Disterhoft JF (1996) Trace eyeblink conditioning increases CA1 excitability in a transient and learning-specific manner. J Neurosci 16:5536-5546.

Moyer JR Jr, Power JM, Thompson LT, Disterhoft JF (2000) Increased excitability of aged rabbit CA1 neurons after trace eyeblink conditioning. J Neurosci 20:5476-5482.

Müller A, Kukley M, Uebachs M, Beck H, Dietrich D (2007) Nanodomains of single $\mathrm{Ca}^{2+}$ channels contribute to action potential repolarization in cortical neurons. J Neurosci 27:483-495.

Nelson AB, Krispel CM, Sekirnjak C, du Lac S (2003) Long-lasting increases in intrinsic excitability triggered by inhibition. Neuron 40:609-620.

Nishimaru K, Eghbali M, Stefani E, Toro L (2004) Function and clustered expression of MaxiK channels in cerebral myocytes remain intact with aging. Exp Gerontol 39:831-839.

Oh MM, Kuo AG, Wu WW, Sametsky EA, Disterhoft JF (2003) Watermaze learning enhances excitability of CA1 pyramidal neurons. J Neurophysiol 90:2171-2179.

Oh MM, McKay BM, Power JM, Disterhoft JF (2009) Learning-related postburst afterhyperpolarization reduction in CA1 pyramidal neurons is mediated by protein kinase A. Proc Natl Acad Sci U S A 106:1620-1625.

Pitler TA, Landfield PW (1990) Aging-related prolongation of calcium spike duration in rat hippocampal slice neurons. Brain Res 508:1-6.

Power JM, Oh MM, Disterhoft JF (2001) Metrifonate decreases sI(AHP) in CA1 pyramidal neurons in vitro. J Neurophysiol 85:319-322.

Power JM, Wu WW, Sametsky E, Oh MM, Disterhoft JF (2002) Age-related enhancement of the slow outward calcium-activated potassium current in hippocampal CA1 pyramidal neurons in vitro. J Neurosci 22:7234-7243.

Santini E, Quirk GJ, Porter JT (2008) Fear conditioning and extinction differentially modify the intrinsic excitability of infralimbic neurons. J Neurosci 28:4028-4036.

Seroussi Y, Brosh I, Barkai E (2002) Learning-induced reduction in postburst after-hyperpolarization (AHP) is mediated by activation of PKC. Eur J Neurosci 16:965-969.

Shah M, Haylett DG (2000) $\mathrm{Ca}^{2+}$ channels involved in the generation of the slow afterhyperpolarization in cultured rat hippocampal pyramidal neurons. J Neurophysiol 83:2554-2561.

Shao LR, Halvorsrud R, Borg-Graham L, Storm JF (1999) The role of BKtype $\mathrm{Ca}^{2+}$-dependent $\mathrm{K}^{+}$channels in spike broadening during repetitive firing in rat hippocampal pyramidal cells. J Physiol 521:135-146.

Storm JF (1987) Action potential repolarization and a fast afterhyperpolarization in rat hippocampal pyramidal cells. J Physiol 385:733-759.

Thibault O, Landfield PW (1996) Increase in single L-type calcium channels in hippocampal neurons during aging. Science 272:1017-1020.

Tombaugh GC, Rowe WB, Rose GM (2005) The slow afterhyperpolarization in hippocampal CA1 neurons covaries with spatial learning ability in aged Fisher 344 rats. J Neurosci 25:2609-2616.

Van der Zee EA, Luiten PG, Disterhoft JF (1997) Learning-induced alterations in hippocampal PKC-immunoreactivity: a review and hypothesis of its functional significance. Prog Neuropsychopharmacol Biol Psychiatry 21:531-572.

Weiss C, Knuttinen MG, Power JM, Patel RI, O'Connor MS, Disterhoft JF (1999) Trace eyeblink conditioning in the freely moving rat: optimizing the conditioning parameters. Behav Neurosci 113:1100-1105.

Weiss C, Preston AR, Oh MM, Schwarz RD, Welty D, Disterhoft JF (2000) The M1 muscarinic agonist CI-1017 facilitates trace eyeblink conditioning in aging rabbits and increases the excitability of CAl pyramidal neurons. J Neurosci 20:783-790.

Wu WW, Oh MM, Disterhoft JF (2002) Age-related biophysical alterations of hippocampal pyramidal neurons: implications for learning and memory. Ageing Res Rev 1:181-207.

Zhang W, Linden DJ (2003) The other side of the engram: experiencedriven changes in neuronal intrinsic excitability. Nat Rev Neurosci 4:885900. 